Annales Geophysicae (2001) 19: 889-897 C European Geophysical Society 2001

\title{
Precipitating clouds observed by 1.3-GHz boundary layer radars in equatorial Indonesia
}

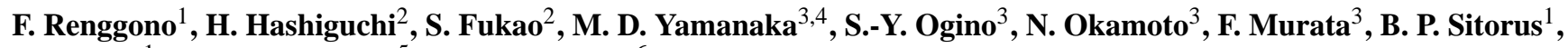 \\ M. Kudsy ${ }^{1}$, M. Kartasasmita ${ }^{5}$, and G. Ibrahim ${ }^{6}$ \\ ${ }^{1}$ Agency for the Assessment and Application of Technology (BPPT), Jakarta Pusat 10340, Indonesia \\ ${ }^{2}$ Radio Science Center for Space and Atmosphere, Kyoto University, Uji, Kyoto 611-0011, Japan \\ ${ }^{3}$ Graduate School of Science and Technology, Kobe University, Nada, Kobe 657-8501, Japan \\ ${ }^{4}$ Frontier Observation Research System for Global Change, Minato-ku, Tokyo 105-0013, Japan \\ ${ }^{5}$ National Institute of Aeronautics and Space (LAPAN), Jakarta Timur 13220, Indonesia \\ ${ }^{6}$ Indonesian Meteorological and Geophysical Agency (BMG), Jalan Angkasa I no 2 Kemayoran, Jakpus 10720, Indonesia
}

Received: 4 September 2000 - Revised: 11 June 2001 - Accepted: 19 June 2001

\begin{abstract}
Temporal variations of precipitating clouds in equatorial Indonesia have been studied based on observations with $1357.5 \mathrm{MHz}$ boundary layer radars at Serpong $\left(6.4^{\circ} \mathrm{S}\right.$, $\left.106.7^{\circ} \mathrm{E}\right)$ near Jakarta and Bukittinggi $\left(0.2^{\circ} \mathrm{S}, 100.3^{\circ} \mathrm{E}\right)$ in West Sumatera. We have classified precipitating clouds into four types: stratiform, mixed stratiform-convective, deep convective, and shallow convective clouds, using the Williams et al. (1995) method. Diurnal variations of the occurrence of precipitating clouds at Serpong and Bukittinggi have showed the same characteristics, namely, that the precipitating clouds primarily occur in the afternoon and the peak of the stratiform cloud comes after the peak of the deep convective cloud. The time delay between the peaks of stratiform and deep convective clouds corresponds to the life cycle of the mesoscale convective system. The precipitating clouds which occur in the early morning at Serpong are dominated by stratiform cloud. Concerning seasonal variations of the precipitating clouds, we have found that the occurrence of the stratiform cloud is most frequent in the rainy season, while the occurrence of the deep convective cloud is predominant in the dry season.
\end{abstract}

Key words. Meteorology and atmospheric dynamics (convective processes; precipitation; tropical meteorology)

\section{Introduction}

The occurrence of deep convection in the tropics plays an important role in the global circulation, since it transports heat, water vapor and so on from the atmospheric boundary layer to the upper troposphere. For instance, the release of latent heat in convective systems in this region drives the Hadley

Correspondence to: H. Hashiguchi

(hasiguti@kurasc.kyoto-u.ac.jp) and Walker circulations. Since the vertical distribution of diabatic heating depends on the vertical structure of the convective system, it is important to study the vertical structure of the precipitating clouds occurring in the tropics.

The vertical structure of tropical mesoscale convective systems (MCSs) has been studied using various instruments during many international campaigns, including GATE (GARP Atlantic Tropical Experiment) in the eastern Atlantic ocean (Williams et al., 1995; Leary and Houze, 1979), EMEX (Equatorial Mesoscale Experiment), winter MONEX in South China Sea, DUNDEE (Down Under Doppler and Electricity Experiment) (Cifelli and Rutledge, 1994), and TOGA-COARE (Tropical Ocean Global Atmosphere, Coupled Ocean-Atmosphere Response Experiment) (Williams and Hacker, 1997; Johnson and Lin, 1997).

In 'Maritime Continent Indonesia', which is surrounded by the warmest sea water in the world, convective clouds are frequently generated. It is pointed out by Murakami and Sumi (1982) that the winter monsoon is centered over Indonesia, while deep convection and heavy rainfall occur throughout this region within this period. Studies concerning the temporal variation of rainfall in this region have been reported by many authors (e.g. Yasunari, 1981; Eguchi, 1983). The study of cloud cluster movement over Indonesia using Geostationary Meteorological Satellite (GMS) data showed that the topography of Indonesia affected the cloud distribution (Nitta et al., 1992).

Since the GMS data provide only horizontal distribution information and it is too costly to launch radiosondes at short intervals over long periods, the usage of UHF wind profilers is useful in studying the structure of the convective system (Gage et al., 1994). For example, a study of precipitating clouds in the tropics using a $915 \mathrm{MHz}$ wind profiler has been done by Williams et al. (1995) on Manus Island. Ohno et al. (2000) used similar radar systems on Biak, Christmas Is- 
Table 1. Specification of the BLR system

\begin{tabular}{ll}
\hline Radar system & Monostatic pulse radar \\
Operating frequency & $1357.5 \mathrm{MHz}$ \\
Antenna & Parabolic antenna $^{(*)}$ \\
Aperture & $3.1 \mathrm{~m}^{2}(2 \mathrm{~m}$ in diameter $)$ \\
Beamwidth & $7.6^{\circ}($ half power $)$ \\
Beam directions & $(\mathrm{Az}, \mathrm{Ze})=\left(0^{\circ}, 0^{\circ}\right),\left(0^{\circ}, 15^{\circ}\right),\left(90^{\circ}, 15^{\circ}\right)$ \\
Transmitter & \\
Peak power & $1 \mathrm{~kW}$ \\
Average power & $20 \mathrm{~W}($ duty ratio $2.0 \%)$ \\
Bandwidth & $4 \mathrm{MHz}$ \\
Pulselength & $0.67,1.0,2.0 \mu \mathrm{s}($ variable $)$ \\
IPP & $50,100,200 \mu \mathrm{s}$ (variable) \\
\hline
\end{tabular}

(*) Serpong BLR: Three fixed parabolic antennas Bukittinggi BLR: Mechanically rotated parabolic antenna

land, and Galapagos Island to study the occurrence of the precipitating clouds along the Pacific Ocean. Ecklund et al. (1999) compared data from a $915 \mathrm{MHz}$ wind profiler with a $3 \mathrm{GHz}$ one in observing the precipitating clouds.

Most of these studies on precipitating clouds have been conducted over islands in the Pacific Ocean. In this paper, a study of the occurrence of precipitating clouds over the maritime continent using $1357.5 \mathrm{MHz}$ boundary layer radars (hereafter referred as to 1.3-GHz BLRs or BLRs) at Serpong $\left(6.4^{\circ} \mathrm{S}, 106.7^{\circ} \mathrm{E}\right)$ and Bukittinggi $\left(0.2^{\circ} \mathrm{S}, 100.3^{\circ} \mathrm{E}\right)$ will be discussed.

\section{Data acquisition and analysis method}

The data used in this study cover 56 months of BLR observations at Serpong (November 1992 to December 1998), 6 months of BLR observations at Bukittinggi (August 1998 to February 1999), and raingauge measurements of surface rainfalls at each radar site. We also launched radiosondes at the Bukittinggi-BLR site every 6 hours during a one week campaign and used the infrared (IR) data from GMS for data inter-comparison.

\subsection{Boundary layer radar observations}

The 1.3-GHz BLRs at Serpong and Bukittinggi are operated at the frequency of $1357.5 \mathrm{MHz}$ with a peak transmitter power of $1 \mathrm{~kW}$. The BLRs were designed to be able to measure the winds in the lower troposphere including the planetary boundary layer (PBL) with time and height resolutions of about $1 \mathrm{~min}$ and $100 \mathrm{~m}$, respectively (Hashiguchi et al., 1995a, b). The only difference between the Serpong and Bukittinggi BLRs is the antenna. The Serpong BLR uses three fixed-position parabolic antennas, while the Bukittinggi BLR uses one parabolic antenna, which is steered towards three different directions in order to estimate the three components of the wind velocity vector. The specification of these BLRs is listed in Table 1.

The topography of the two BLR sites is quite different.

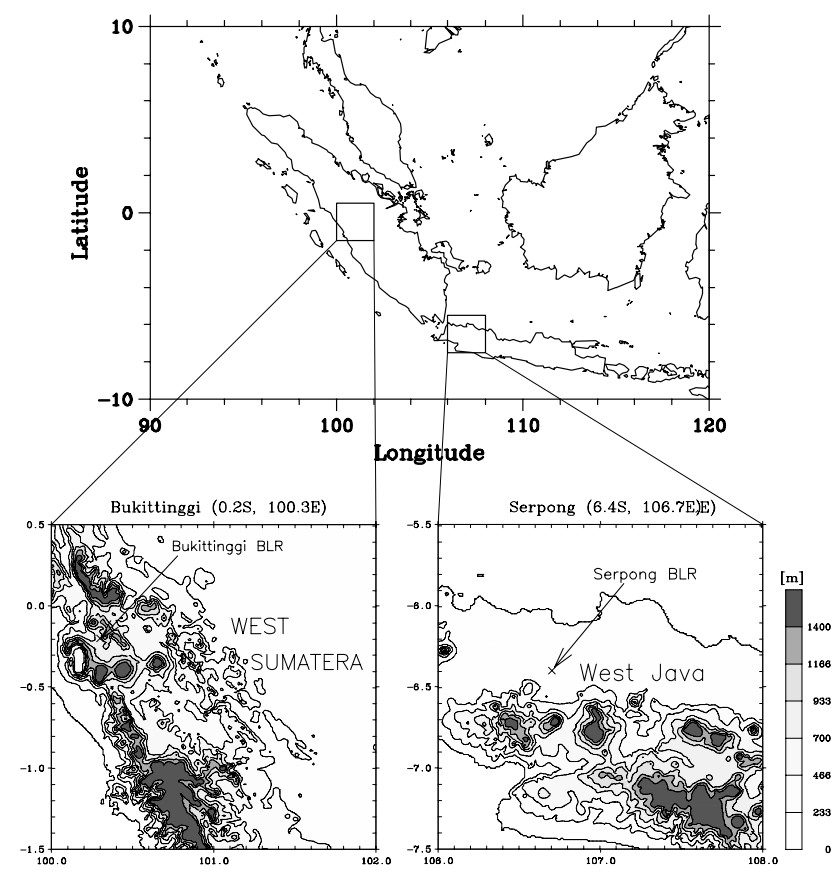

Fig. 1. Map around the BLR sites at Serpong (right panel) and Bukittinggi (left panel), Indonesia. Contours indicate the altitude above sea level. Cross signs $(x)$ indicate the places of radar sites.

The Serpong BLR, which is installed inside the PUSPIPTEK (National Center for Research, Science, and Technology) area in the southwest suburbs of Jakarta, is located in a relatively flat area at the altitude of about $50 \mathrm{~m}$ above sea level, while the Bukittinggi BLR, which is installed inside the Global Atmosphere Watch (GAW) Observatory of Indonesian Meteorological and Geophysical Agency (BMG) at Kototabang, Bukittinggi, West Sumatera, is situated at the top of a small hill with the altitude of $864 \mathrm{~m}$ above sea level (see Fig. 1).

Although these BLRs are designed to observe the clear air, earlier studies showed that $1.3-\mathrm{GHz}$ BLRs can also be used to detect the hydrometeors. The use of an operating frequency of $1357.5 \mathrm{MHz}$ makes the echo intensity from the precipitation much stronger than the atmospheric turbulence echoes. It is expected that the $1.3-\mathrm{GHz}$ BLR can obtain precipitation echoes of up to $60 \mathrm{~dB}$ more intense than the atmospheric turbulence echoes under typical conditions (Hashiguchi et al., 1995a). Therefore, height coverage increases up to the $6.4 \mathrm{~km}$ height (which is the maximum sampling height) when precipitation particles (rain, snow, graupel, hail, etc.) exist.

Figure 2(a) is an example of the Doppler spectra during stratiform precipitation obtained by the Bukittinggi BLR at 1721 LT on 4 October 1998. In the right panel, the enhancement of the equivalent radar reflectivity with the melting layer, denoted by the radar bright-band, appears around $3.8 \mathrm{~km}$. This enhancement is associated with the melting of ice particles to liquid water drops. The sharp drop-off of 

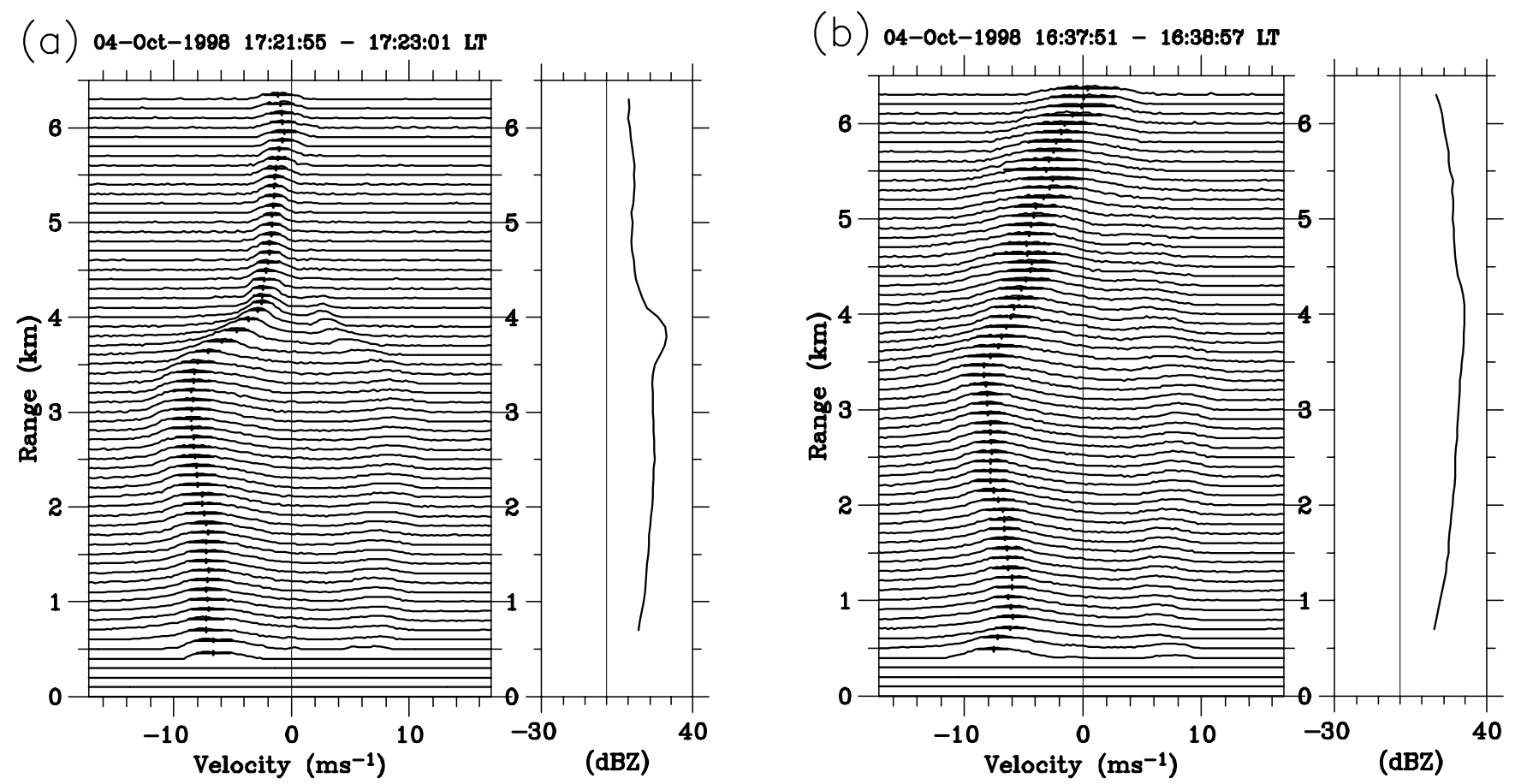

Fig. 2. Doppler spectra obtained by a vertical beam of Bukittinggi BLR at (a) 1721 LT and (b) 1637 LT on 4 October 1998 . Left panels are the Doppler velocity spectra with thick vertical lines, indicating mean Doppler velocity and thick horizontal lines representing spectral width. The vertical profiles of equivalent radar reflectivity are plotted in the right panels.

reflectivity in the lower portion of the melting layer is produced by two effects. If the melting process is completed and all particles collapse to form smaller size rain drops, then the reflectivity decreases. If its process is in the steady stratiform rain, the mean concentration of rainwater must decrease sharply, which corresponds to the decrease in reflectivity (Houze, 1993). Together with the decrease in the reflectivity, the fall speed of the particles suddenly increases. As can be seen in the left panel, the downward velocity, which is indicated by the negative Doppler velocities, increases from $2 \mathrm{~ms}^{-1}$ to $9 \mathrm{~ms}^{-1}$. Note that these Doppler spectra are the convolution of the fall velocity spectra associated with the hydrometeor size distribution and the air motion spectra, and that spectral peaks of positive Doppler are artificial due to the imperfection of quadrature detection in the receivers. These positive image peaks could be corrected by an appropriate processing technique, if the raw I/Q data are available. However, we record only Doppler spectra in standard observations. Below the $3.5 \mathrm{~km}$ height, the backscattering echoes are due to rain drops, and the precipitation particles in this region simply fall to the ground at an almost constant rate.

Figure 2(b) is the Doppler spectra for the convective precipitation obtained at 1637 LT on 4 October 1998. It is clearly seen that the radar reflectivity is intense throughout the whole height range, and no melting layer and no sharp decrease in the fall speed profile are found. Above the $0^{\circ} \mathrm{C}$ level $(>$ $4 \mathrm{~km}$ ), the spectral width, which is indicated by thick hori- zontal lines, is larger than that below the melting level. The changes in spectral width near the freezing level are more likely associated with acceleration above the freezing level due to the release of latent heat and decreased precipitation loading (May and Rajopadhyaya, 1996, 1999).

\subsection{Classification of precipitating clouds}

Precipitation data of BLR observations have been chosen based on large values of reflectivity and Doppler velocity (fall speed). To determine the thresholds of reflectivity and fall speed, we used data obtained by Serpong BLR and a raingauge (IKEDA, RT-5) installed at the radar site. If $0.5 \mathrm{~mm}$ or more of rainfall in $1 \mathrm{~min}$ is detected by the raingauge, the BLR echoes at that time are considered as the echoes from precipitation. After having evaluated 56 months of BLR data, a total of $5544 \mathrm{~min}$ of rain data with their corresponding reflectivity and fall speed derived from BLR was accumulated. Figure 3 shows the frequency distribution of reflectivity factor vs. vertical Doppler velocity for all data when the raingauge detected rain. The distribution of the vertical velocity and the reflectivity are within -3 to $-12 \mathrm{~ms}^{-1}$ and 0 to $42 \mathrm{dBZ}$, respectively. This vertical velocity indicates the drop speed of precipitation particles relative to the ground and not the atmospheric motion. In this study, we choose $18 \mathrm{dBZ}$ for the equivalent reflectivity and $-3 \mathrm{~ms}^{-1}$ for vertical velocity as the thresholds, since many radar echoes weaker than $18 \mathrm{dBZ}$ did not correspond to raingauge measurements.

To determine the precipitating cloud type from BLR data, 


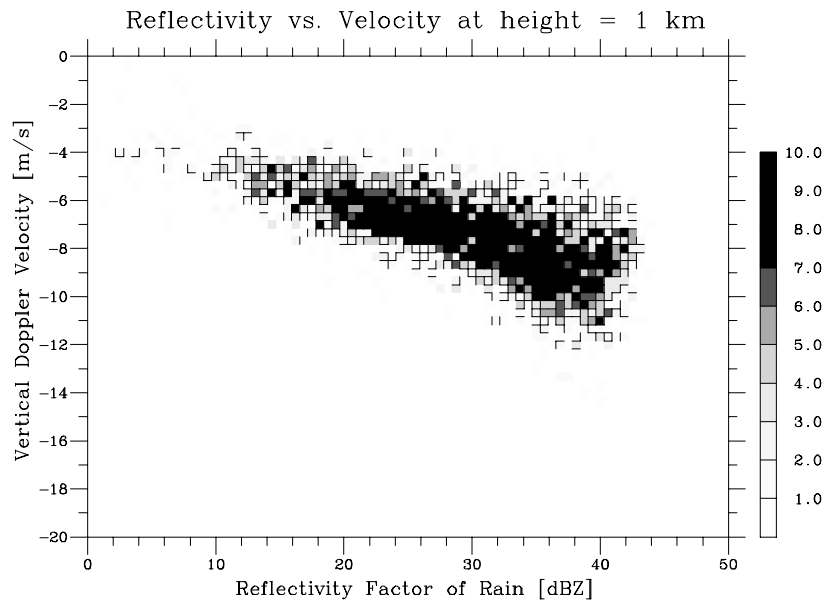

Fig. 3. Frequency distribution of the equivalent radar reflectivity vs. vertical Doppler velocity at $1 \mathrm{~km}$ height for all BLR data when the surface raingauge detected rain from November 1992 to December 1998.

the 30-min averaged reflectivity, Doppler velocity, and spectral width derived from the vertical-pointing beam are calculated. From the vertical structure of the precipitating clouds, we have classified each profile into 4 types of clouds, i.e. stratiform, mixed stratiform-convective, deep convective, and shallow convective clouds, using the algorithm developed by Williams et al. (1995). This algorithm is based on judgment of the presence of a melting layer and the presence of turbulence or hydrometeors above the melting layer. The terms of type $\mathrm{S}, \mathrm{M}, \mathrm{D}$, and $\mathrm{C}$ are hereafter used to refer to stratiform, mixed stratiform-convective, deep convective, and shallow convective clouds, respectively.

\section{Case study at Bukittinggi during observation campaign period}

The observation campaign at Bukittinggi was conducted in the rainy season during 27 September to 6 October 1998. $50.5 \mathrm{~mm}$ of rain was observed at the radar site by a standard tipping-bucket type automatic raingauge (Ogasawara, C-R203) during 10 days of the campaign, while the monthly rainfall amount in October in this area is usually more than $200 \mathrm{~mm}$. During the campaign, radiosonde (AIR, GPS-5A1) observations were conducted every 6 hours to measure the height profiles of pressure, temperature, humidity, and winds.

GMS-IR imageries over the Bukittinggi area during the campaign period are shown in Fig. 4. This figure shows the time-longitude cross section of the $T_{\mathrm{BB}}$ index $\left(I_{\mathrm{TBB}}\right)$ along the $0.2^{\circ} \mathrm{S}$ latitude of the radar site. $I_{\mathrm{TBB}}$ is defined as

$I_{\mathrm{TBB}}= \begin{cases}250-T_{\mathrm{BB}} & \left(T_{\mathrm{BB}} \leq 250 \mathrm{~K}\right) \\ 0 & \left(T_{\mathrm{BB}}>250 \mathrm{~K}\right)\end{cases}$

where $T_{\mathrm{BB}}$ is the area mean equivalent black body temperature in Kelvins (e.g. Nakazawa, 1988; Hashiguchi et al.,

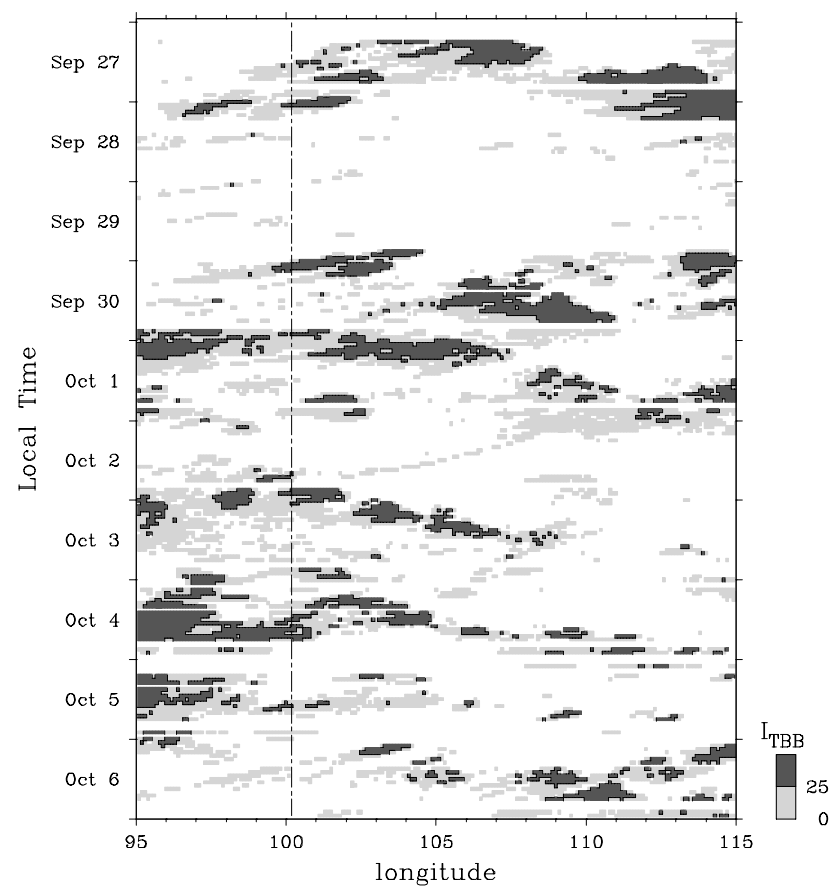

Fig. 4. Time-longitude cross section of the $T_{\mathrm{BB}}$ index $\left(I_{\mathrm{TBB}}\right)$ along the $0.2^{\circ} \mathrm{S}$ latitude obtained from hourly GMS-IR data from 27 September to 6 October 1998 . The vertical line indicates the longitude of the radar site $\left(100.3^{\circ} \mathrm{E}\right)$.

1995b). We use $I_{\mathrm{TBB}}$ in order to select deep convective clouds and to exclude data from sea surface and lower clouds. The GMS-IR data have spatial and time resolutions of $0.1^{\circ}$ longitude $\times 0.1^{\circ}$ latitude and one hour, respectively. During the campaign, cloud clusters passed over the radar site several times. The occurrence of these precipitating clouds was also monitored by the BLR at Bukittinggi, as well as by other surface measurement instruments at the radar site.

The comparison of cloud type classified from BLR observations with the $T_{\mathrm{BB}}$ index and the surface rainfall is shown in Fig. 5. Since GMS-IR only represents the cloud top temperature, we cannot determine the vertical structure of the cloud only by analyzing the $I_{\mathrm{TBB}}$ value. The high value of $I_{\mathrm{TBB}}$ could be obtained from the anvil which lies above it. For example, at midnight on 1 October 1998 , the $I_{\mathrm{TBB}}$ is about $17\left(T_{\mathrm{BB}}=233 \mathrm{~K}\right.$ which corresponds to approximately the $11 \mathrm{~km}$ height), but no rainfall is detected and the observations from the BLR do not show any hydrometeors.

Of the total rainfall amount of $50.5 \mathrm{~mm}$ recorded by the raingauge at Bukittinggi during the observation campaign, $20.5 \mathrm{~mm}$ came from the rain which occurred on 4 October 1998. During this day, the westward moving clouds passed over the radar site and covered the Bukittinggi area for about 6 hours. Figure 6 shows the cloud distribution taken from the GMS-IR data at 1600 LT on 4 October 1998. It is shown that almost the whole west part of the island, including over the radar site, is covered by the clouds. Figure 7 shows the results from the BLR observations (upper panel) and from 


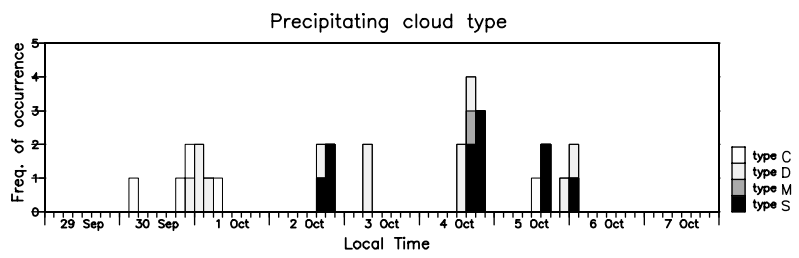

$\operatorname{GMS}\left(0.1^{\circ} \times 0.1^{\circ}\right)$ at $(0.2 \mathrm{~S}, 100.2 \mathrm{E})$
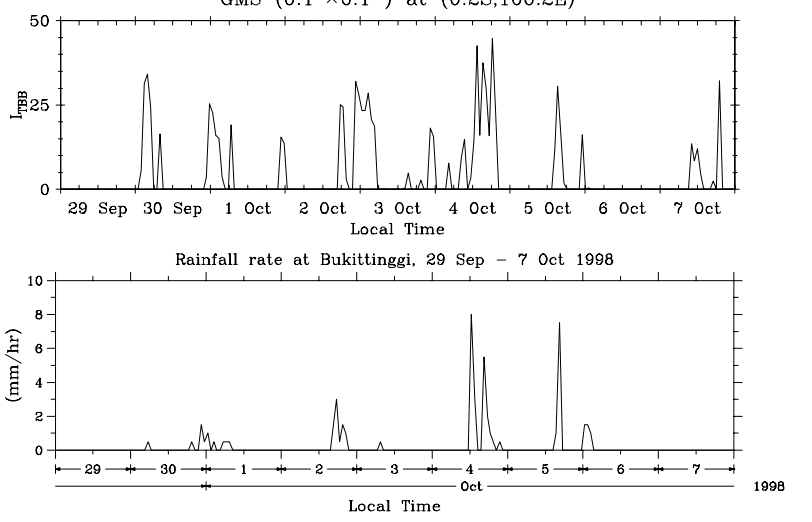

Fig. 5. (a) Occurrence frequency of precipitating clouds classified from BLR data every 3 hours. (b) $T_{\mathrm{BB}}$ index from GMS-IR at $\left(0.2^{\circ} \mathrm{S}, 100.3^{\circ} \mathrm{E}\right)$. (c) Rainfall rate averaged every 1 hour.

the raingauge (lower panel) during 1000-2400 LT on 4 October 1998. During 1230-1430 LT (first group) and 16002130 LT (second group), BLR detected hydrometeors in the height range of $0.5-6.4 \mathrm{~km}$. The vertically oriented cores of high reflectivity appear around 1300 LT and during 1600$1700 \mathrm{LT}$, and they are marked by relatively heavy rainfalls at the surface. After $1700 \mathrm{LT}$, the bright-band appears with weak rainfall for several hours. The vertical structure of the second group of clouds corresponds to the schematic model of the mesoscale convective system (MCS), mentioned by Leary and Houze (1979), under the assumption that the deep convective and stratiform clouds are moving with constant horizontal speed at all height levels. It is suspected that the stratiform cloud in the trailing region was supplied with ice particles which were spread from the deep convective cloud. Total rainfall amount from the first and second groups of clouds are $11 \mathrm{~mm}$ and $9.5 \mathrm{~mm}$, respectively.

The results of cloud classification are shown as circled characters in the upper panel of Fig. 7. S, M, and D indicate the stratiform, mixed stratiform-convective, and deep convective clouds, respectively. The first group of clouds is classified as cloud type $\mathrm{D}$, and the second group is classified as cloud type D followed by type $S$. The cloud type $M$ appears between the occurrences of cloud types $D$ and $S$ in the second group. Note that the use of 30-min averaged data for classifying the clouds could cause a misanalyzation of cloud type M. In the future work, we are going to utilize each profile of data for the better results.

The triangles $(\Delta)$ at the surface in Fig. 7 indicate the launching time of the radiosondes. The Skew $T-\log P$ diagrams for sondes A (launched at $1230 \mathrm{LT}$ ) and B (launched at 1814 LT) are shown in Figs.8(a) and (b), respectively. The result from

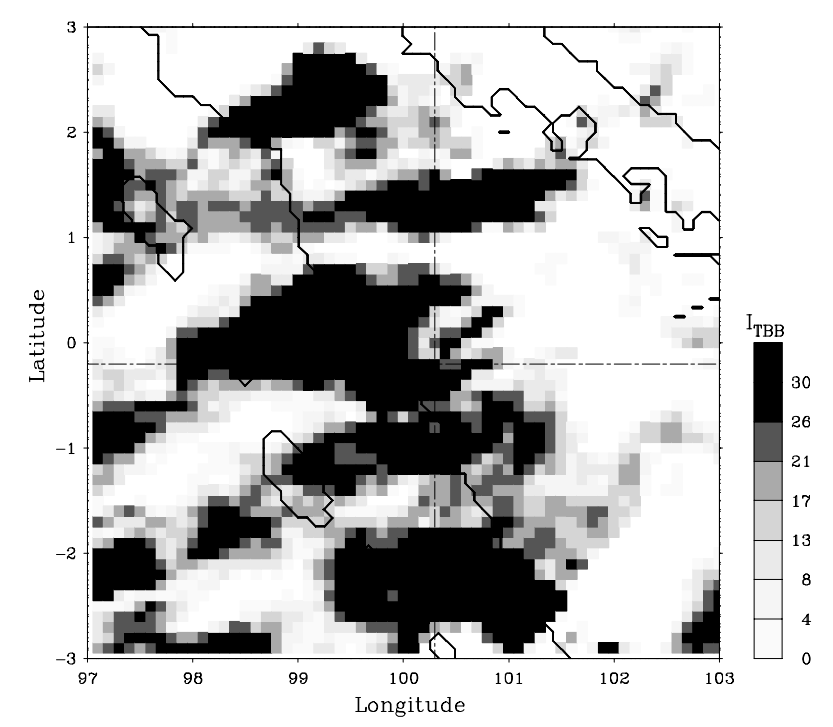

Fig. 6. GMS-IR imagery taken at 1600 LT on 4 October 1998. The crossing between horizontal and vertical lines indicate the BLR site $\left(0.2^{\circ} \mathrm{S}, 100.3^{\circ} \mathrm{E}\right)$.

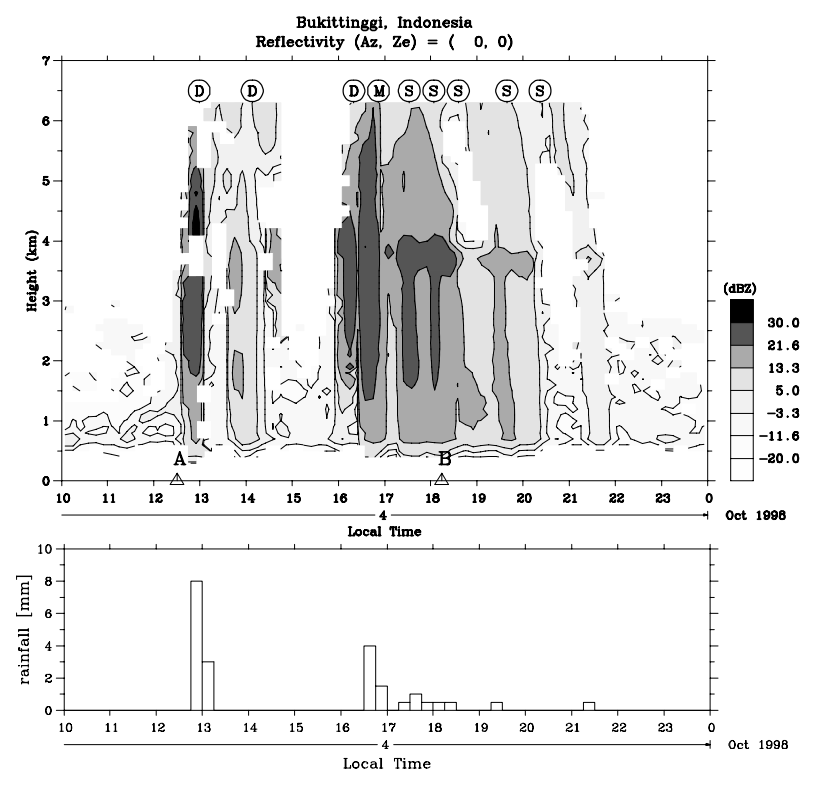

Fig. 7. Time-height cross section of the radar reflectivity observed with the Bukittinggi BLR averaged every $10 \mathrm{~min}$ (upper panel), and the rainfall accumulation for every $15 \mathrm{~min}$ (lower panel) during 1000-2400 LT on 4 October 1998. In the upper panel, the triangles $(\Delta)$ at the surface indicate the radiosonde launching time and the circled characters (S, M, and D) indicate cloud types of the stratiform, mixed stratiform-convective, and deep convective, respectively.

the sonde A launched about $20 \mathrm{~min}$ before the rain shows a relatively dry surface layer with nearly saturated conditions between $850 \mathrm{hPa}$ and $450 \mathrm{hPa}$. This layer is also characterized by a westerly flow extending from $800 \mathrm{hPa}$ up to $400 \mathrm{hPa}$. Above $400 \mathrm{hPa}$, the flow reverses to northeasterly. 

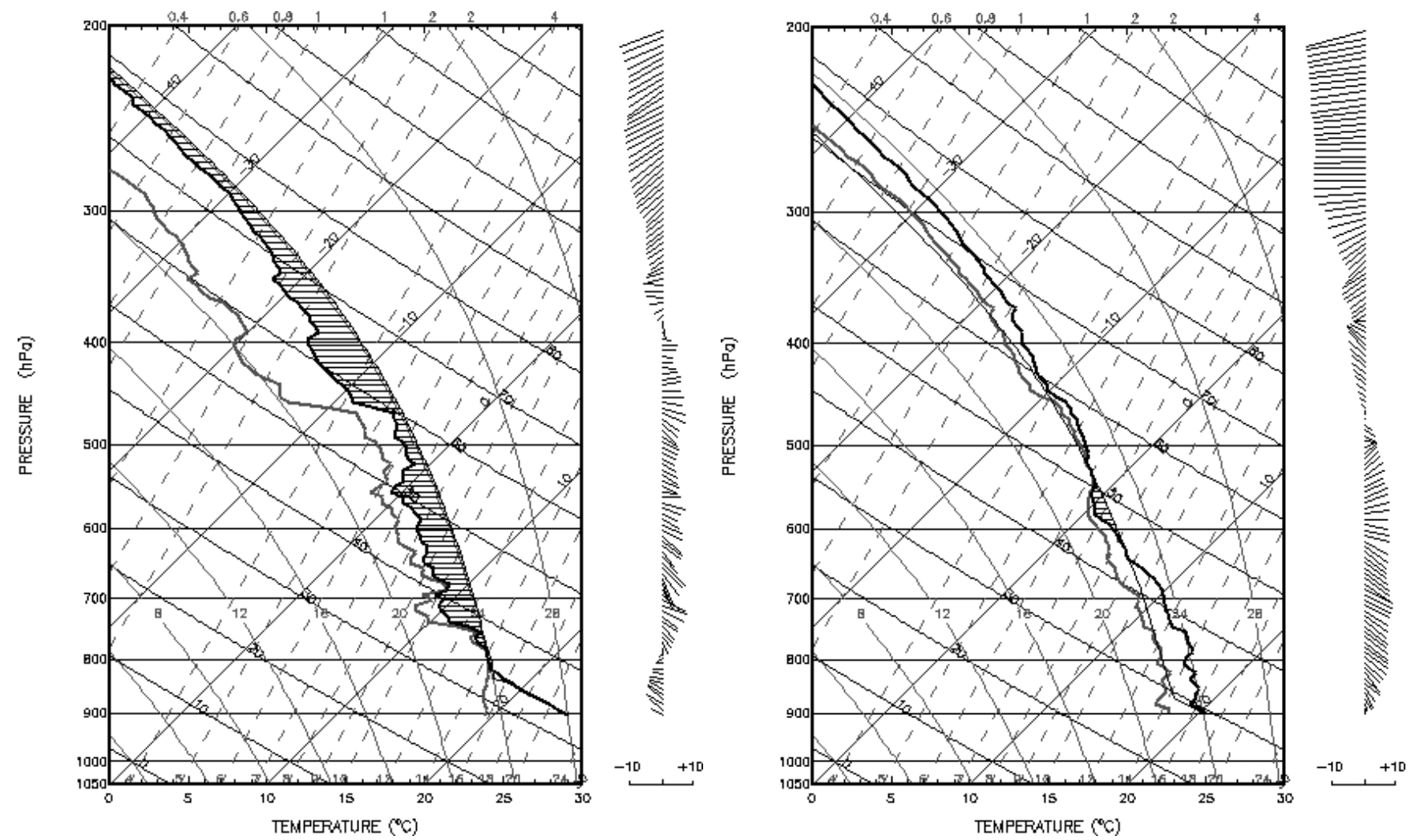

Fig. 8. Skew $T-\log P$ diagram derived from radiosonde observations launched at (a) 1230 LT and (b) 1814 LT on 4 October 1998 . Temperature and dew point traces $\left({ }^{\circ} \mathrm{C}\right)$ are indicated by the thick solid and thin curves, respectively. Wind data are shown in the right portion of the figure with wind speed $\left(\mathrm{ms}^{-1}\right)$ and direction represented by the length and inclination of the lines, respectively.

The shaded area in this figure represents the buoyant stability of the environment, which is termed the CAPE. The positive energy region appears from $815 \mathrm{hPa}$ to $170 \mathrm{hPa}$ with the CAPE value of $1297 \mathrm{~J} / \mathrm{kg}$. This value represents the unstable condition of the atmosphere which drives into deep convective, as it is also observed by BLR on 1245 LT (see Fig. 7). Figure $8(\mathrm{~b})$ shows the results from the sonde B launched at 1814 LT during the appearance of the melting layer. The atmospheric condition during this time is stable and relatively humid. It was nearly saturated between $600 \mathrm{hPa}$ and $450 \mathrm{hPa}$, which corresponds to the occurrence of the nimbostratus cloud observed by BLR. The westerly flow extends from surface to $500 \mathrm{hPa}$, and the flow reverses to easterly above $500 \mathrm{hPa}$. This upper level wind could cause the cloud spread to the rear side and make an anvil cloud.

\section{Diurnal and annual variations}

The type of precipitating clouds which occur over the radar sites varies in vertical structure as well as in occurrence time, as described in the previous section. In order to investigate the characteristics of the occurrence of each cloud type, a long period of data obtained by the Serpong and Bukittinggi BLRs has been analyzed. Figures 9 and 10 show the annual and diurnal variations of cloud occurrence observed by the BLRs.

The annual variation at Serpong is shown in the left panel of Fig. 9. The occurrences of stratiform and deep convective clouds have annual variations, while the mixed and shallow convective clouds are almost flat through a year. From November to February, which is the rainy season in Java, the occurrence of stratiform cloud reaches the maximum and is most frequent among the four types. The occurrence ratio between stratiform and deep convective clouds during this period is about 3:2, which is consistent with the results found in studies of tropical oceanic and continental convection using Doppler radars (Houze, 1977; Williams et al., 1995). From March to October, the occurrence of deep convective cloud is predominant, although the occurrence of the precipitating clouds is not as frequent as during the rainy season.

From the studies using GMS data, Nitta and Sekine (1994) mentioned that the diurnal variation of cloud activities is predominant in Indonesia. The diurnal variation of the precipitating clouds observed by BLR at Serpong is shown in the right panel of Fig. 9. Almost all of the precipitating clouds occur in the afternoon (during 1400-1900 LT). This is consistent with the result of the diurnal variation of rainfall at Serpong, as reported by Hamada (1995). The peak of stratiform cloud has a smaller value and comes later than the deep 

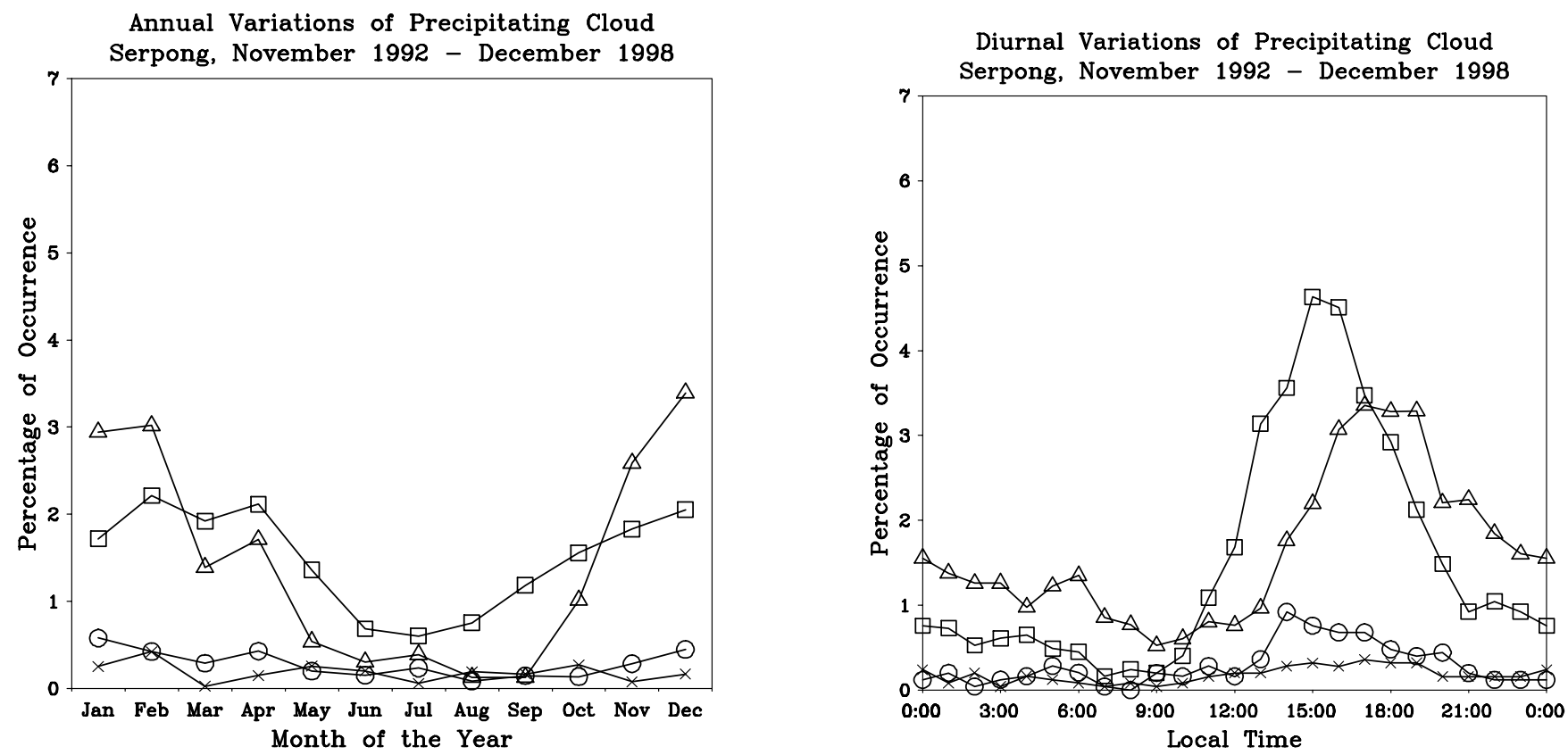

Fig. 9. Annual (upper panel) and diurnal (lower panel) variations of precipitating clouds at Serpong. The triangles, circles, squares, and crosses indicate stratiform, mixed, deep convective and shallow convective cloud.
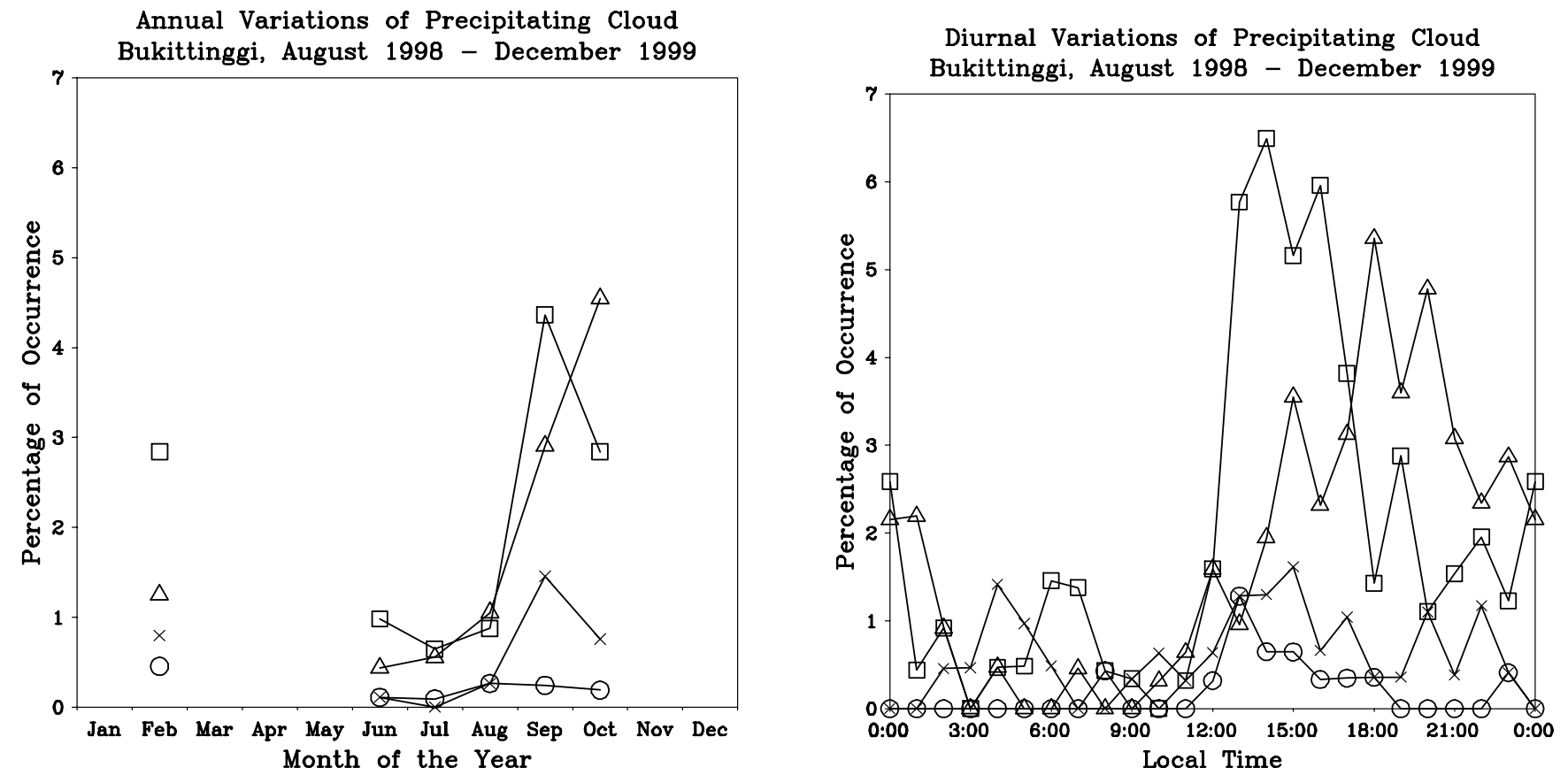

Fig. 10. Same as Fig. 9, but at Bukittinggi. No data or not enough data are available for January, March to May, and November to December.

convective cloud. This time delay is consistent with the evolution of the MCS cloud, which often contains stratiform precipitation. The stratiform cloud also appears in the morning and has a small peak at 0600 LT.

Since the geographical condition of Bukittinggi is different from Serpong, the occurrence of precipitating clouds is also different. Hamada (1995) analyzed rainfall variations at Bukittinggi and revealed that this area has a semiannual variation with two rainy seasons (March to May and September to November) per year. The diurnal and annual variations of precipitating clouds at Bukittinggi are shown in Fig. 10. This figure is the average of the cloud occurrence obtained 
by BLR from the end of August 1998 to the beginning of December 1999. Due to some system trouble, the observations stopped during the March to May 1999 time period. The left panel of Fig. 10 shows the annual variation for each type of cloud. The precipitating clouds have their peak of occurrence from September to October. The dominant occurrence of deep convective cloud in the beginning of the rainy season (September) agrees with the characteristics at Serpong. However, the analysis of seasonal variations of precipitating cloud occurrence at Bukittinggi has not been completed yet, because the available data are insufficient.

The diurnal variation in the right panel of Fig. 10 is consistent with that of surface rainfall. Most of the clouds occur in the afternoon, with the peak of occurrence during 13002000 LT. The peak of deep convective cloud occurs earlier than that of stratiform cloud. The occurrence of deep convective cloud increases at $1200 \mathrm{LT}$, reaches the peak at 1400 LT, and decreases to about $2 \%$ at 1800 LT. On the other hand, the occurrence of stratiform cloud starts to increase at 1300 LT, and reaches the peak at 1800 LT. From 2100 LT, it gradually decreases until reaching the lower level at 0300 LT. The occurrence of precipitating clouds during this period is consistent with the result from the averaged diurnal variation of rainfall. The lowest occurrence for all types appears during 0900-1100 LT.

\section{Concluding remarks}

The 1.3-GHz BLR is sensitive to hydrometeors as well as fluctuations of the radar refractive index in the clear air. In order to study the precipitation at Serpong and Bukittinggi, the vertical structure of precipitating clouds has been examined by using data obtained from the vertical beam of BLRs. It has been confirmed that during the occurrence of stratiform cloud, radar bright-band is observed by BLR as an increase of radar reflectivity below the melting level. During the occurrence of deep convective cloud, intense reflectivity is detected at the whole sampling height range.

From the BLR observations, we have reached the following conclusions:

- In the rainy season, precipitating clouds were often observed. The average occurrence of precipitating clouds was more than $5 \%$ every month in the rainy season and less than $2 \%$ in the dry season, except for the transition period of seasons.

- In the rainy season (November to February) at Serpong, the occurrence of stratiform cloud was the most frequent of all types, but in the dry season, the occurrence of deep convective cloud was predominant.

- The peak of precipitating cloud occurrence appeared at Bukittinggi from September to November. This result is consistent with the earlier study using rainfall data (e.g. Hamada, 1995).
- Diurnal variations at Serpong and Bukittinggi showed the same characteristics. Precipitating clouds occurred primarily in the afternoon. The peak of stratiform cloud came after the peak of deep convective cloud. The time delay between the peaks of stratiform cloud and deep convective cloud in the afternoon corresponded to the life cycle of the mesoscale convective system.

- Precipitating cloud which occurred in the early morning at Serpong was dominated by stratiform cloud.

In this paper, precipitating clouds observed with BLRs have been quantitatively and qualitatively studied. In subsequent papers, we will compare our results with other observation data, for example, with the data from TRMM (Tropical Rainfall Measuring Mission).

Acknowledgements. The authors wish to thank Prof. T. Tsuda and Dr. M. Yamamoto of RASC, Kyoto University for their valuable comments and suggestions. They also thank Dr. T. Ohsawa of Gifu University for providing the GMS-IR data and all operators who maintain the BLRs at Serpong and Bukittinggi. They thank Mr. G. Hassenpflug of RASC for their careful reading of the original manuscript with constructive comments. The present study was financially supported by Grants-in-Aids (09041106) of the Japanese Ministry of Education, Culture, Sports, Science, and Technology.

Topical Editor J.-P. Duvel thanks P. May and another referee for their help in evaluating this paper

\section{References}

Cifelli, R. and Rutledge, S., Vertical motion structure in maritime continent mesoscale convective systems: Results from $50-\mathrm{MHz}$ profilers, J. Atmos. Sci., 51, 2631-2652, 1994.

Ecklund, W. L., Williams, C. R., Johnston, P. E., and Gage, K. S., A 3-GHz profiler for precipitating cloud studies, J. Atmos. Oceanic Technol., 16, 309-322, 1999.

Eguchi, T., Rainfall distribution and air streams over Indonesia, Geographical Review of Japan, 56, 151-170, 1983 [in Japanese].

Gage, K. S., Williams, C. R., and Ecklund, W. L., UHF wind profilers: A new tool for diagnosing tropical convective cloud systems, Bull. Amer. Meteor. Soc., 75, 2289-2294, 1994.

Hamada, J., Climatological study on rainfall variation in Indonesia, Master's thesis, Geophysical Institute, Kyoto University, 1995.

Hashiguchi, H., Fukao, S., Tsuda, T., Yamanaka, M. D., Tobing, D. L., Sribimawati, T., and Harijono, S. W. B., Observations of the planetary boundary layer over equatorial Indonesia with an L-band clear-air Doppler radar: Initial results, Radio Sci., 30, 1043-1053, 1995a.

Hashiguchi, H., Fukao, S., Yamanaka, M. D., Tsuda, T., Harijono, S. W. B., and Wiryosumarto, H., Boundary layer radar observations of the passage of the convection center over Serpong, Indonesia $\left(6^{\circ} \mathrm{S}, 107^{\circ} \mathrm{E}\right)$ during the TOGA COARE intensive observation period, J. Metor. Soc. Japan, 73, 535-548, 1995 b.

Houze, Jr., R. A., Structure and dynamics of a tropical squall line system, Mon. Wea. Rev., 105, 1540-1567, 1977.

Houze, Jr., R. A., Cloud dynamics, Academic Press Inc., pp. 573, 1993.

Johnson, H. and Lin, X., Episodic trade wind regimes over the western pacific warm pool, J. Atmos. Sci, 54, 2020-2034, 1997. 
Leary, C. A. and Houze, Jr., R. A., The structure and evolution of convection in tropical cloud cluster, J. Atmos. Sci, 36, 437-457, 1979.

May, P. T. and Rajopadhyaya, D. K., Wind profiler observations of vertical motion and precipitation microphysics of a tropical squall line, Mon. Wea. Rev., 124, 621-633, 1996.

May, P. T. and Rajopadhyaya, D. K., Vertical velocity characteristics of deep convection over Darwin, Australia, Mon. Wea. Rev., 127, 1056-1071, 1999.

Murakami, T. and Sumi, A., Southern hemisphere summer monsoon circulation during the 1978-79 WMONEX. Part I: Monthly mean wind fields, J. Metor. Soc. Japan, 60, 823-839, 1982.

Nakazawa, T., Tropical super clusters within intraseasonal variations over the western Pacific, J. Metor. Soc. Japan, 66, 823-839, 1988.

Nitta, T., Mizuno, T., and Takahashi, K., Multi-scale convective systems during the initial phase of the 1986/87 El Niño, J. Metor.
Soc. Japan, 70, 447-466, 1992.

Nitta, T. and Sekine, S., Diurnal variation of convective activity over the tropical western pacific, J. Metor. Soc. Japan, 72, 627-641, 1994.

Ohno, Y., Williams, C. R., and Gage, K. S., Climatological study of rain types using UHF wind profilers in the tropical Pacific and Asia, Proceedings of The Ninth Workshop on Technical and Scientific Aspects of MST Radar, Toulouse, France, 337-340, 2000.

Williams, A. G. and Hacker, J. M., Transport process in the tropical warm pool boundary layer. Part II: Vertical structure and variability, J. Atmos. Sci., 54, 2060-2082, 1997.

Williams, C. R., Ecklund, W. L., and Gage, K. S., Classification of precipitating clouds in the tropics using $915-\mathrm{MHz}$ wind profilers, J. Atmos. Oceanic Technol., 12, 996-1012, 1995.

Yasunari, T., Temporal and spatial variations of monthly rainfall in Java, Indonesia, Southeast Asian Studies, 19, 170-186, 1981. 